\title{
Perbandingan Laju Lindi Landfill Kelas I dan II untuk Limbah NORM dari Industri Minyak dan Gas Bumi Menggunakan Model Hydrologic Evaluation of Landfill Performance (HELP)
}

\author{
Comparison of Leachate Rate of Class I and Class II Landfill \\ for NORM Waste from Oil and Gas Industries \\ Using Hydrologic Evaluation of Landfill Performance (HELP) Model
}

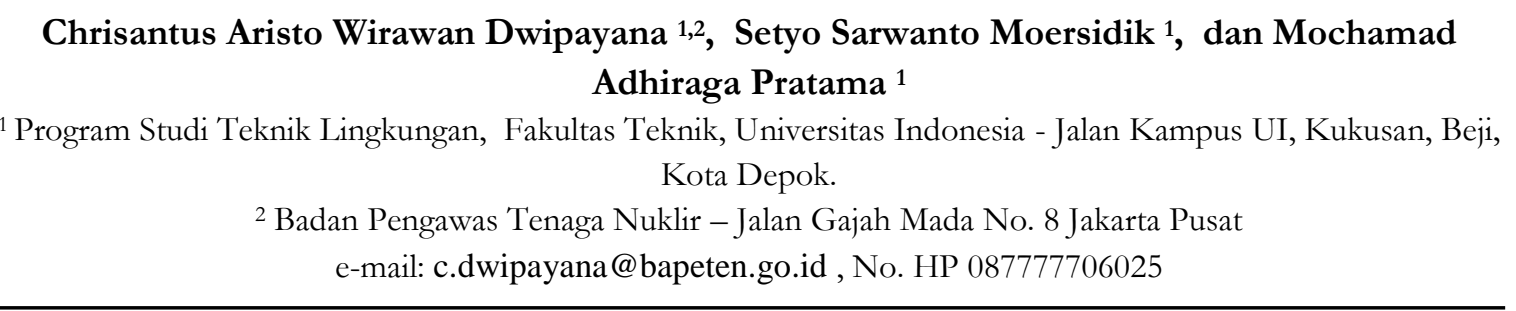

\begin{abstract}
ABSTRAK
Dalam proses produksi minyak dan gas dapat menghasilkan sejumlah besar Naturally Occurring Radioactive Materials (NORM) dengan konsentrasi radioaktivitas yang meningkat sebagai limbah hasil samping. Metode pembuangan NORM yang saat ini digunakan dalam industri minyak \& gas adalah landfill, land-spreading, surface burial, underground injection, off-shore discharge. Ancaman terbesar terhadap air tanah yang ditimbulkan oleh landfill adalah air lindi. Pada penelitian ini akan dilakukan perbandingan laju lindi landfill Kelas I dan Kelas II berdasarkan hasil menggunakan software pemodelan Hydrologic Evaluation of Landfill Performance (HELP) yang dikembangkan oleh United States Environmental Protection Agency (US EPA). Untuk fase operasional ditemukan perbedaan laju lindi dari lapisan dasar yang signifikan antara landfill Kelas I dan Kelas II. Untuk fase setelah penutupan limbah, landfill kelas I dan kelas II memiliki kinerja yang sama dalam hal menahan laju produksi air lindi.
\end{abstract}

Kata kunci : NORM; landfill; lindi; HELP

ABSTRACT

In the process of oil and gas production, it can produce large amounts of Naturally Occurring Radioactive Materials (NORM) with increased radioactivity as by-products. NORM disposal methods currently used in the oil \& gas industry are landfills, land-spreading, surface burial, underground injection, off-shore discharge. The biggest threat to groundwater caused by landfills is leachate. This study is a comparison of the leachate rates of Class I and Class II Landfill results using the Hydrologic Evaluation of Landfill Performance (HELP) modeling software developed by the United States Environmental Protection Agency (US EPA). For the operational phase, there were significant differences in leachate rate from the base layer between Class I and Class II landfills. For the phase after closure of waste, Class I and Class II landfills have the same performance in terms of holding back the rate of leachate.

Keywords : NORM, landfill; leachate, HELP

Cara Mengutip : Dwipayana, C., Moersidik, S. S., Pratama, M. A. (2019). Perbandingan Laju Lindi Landfill Kelas I dan II untuk Limbah NORM dari Industri Minyak dan Gas Bumi Menggunakan Model Hydrologic Evaluation of Landfill Performance (HELP). Reka Buana : Jurnal Ilmiah Teknik Sipil dan Teknik Kimia, 4 (2), $77-$ 84. http://dx.doi.org/10.33366/rekabuana.v4i2.1306 


\section{PENDAHULUAN}

Dalam proses produksi minyak dan gas dapat menghasilkan sejumlah besar Naturally Occurring Radioactive Materials (NORM) dengan konsentrasi radioaktivitas yang meningkat sebagai limbah hasil samping [1]. NORM dapat terakumulasi pada sludge, scale, lumpur atau sedimen [2]. Kegiatan yang terkait dengan peningkatan radioaktivitas NORM yang tidak terkendali dapat mengkontaminasi lingkungan dan memberi risiko terhadap kesehatan manusia. Bahaya yang ditimbulkan oleh peningkatan radioaktivitas NORM bukan merupakan bahaya yang seketika muncul, namun dalam kurun waktu yang lama, akumulasi dosis radiasi dapat menjadi sangat signifikan [3].

Untuk memastikan bahwa semua aspek manajemen NORM diperhatikan, terstruktur dan dikelola, siklus proses berikut harus dikembangkan dengan baik. Siklus proses dimulai dengan pemantauan NORM, identifikasi NORM, perlindungan pekerja, tindakan pengendalian kontaminasi, dekontaminasi, penyimpanan limbah NORM sementara, dan akhirnya adalah pembuangan limbah NORM permanen (OGP, 2008). Metode pembuangan NORM yang saat ini digunakan dalam industri minyak \& gas adalah landfill, land-spreading, surface burial, underground injection, off-shore discharge [4].

Di Indonesia, terdapat beberapa peraturan yang mengatur tentang pengelolaan NORM. Ketentuan terkait penimbunan NORM diatur dalam Peraturan Pemerintah Nomor 101 Tahun 2014 tentang Pengelolaan Limbah Berbahaya dan Beracun. Terminologi yang digunakan tidak secara eksplisit menyebutkan NORM atau TENORM tetapi limbah B3 terkontanimasi radioaktif [5]. Ketentuan lebih lanjut diatur dalam Peraturan Menteri Lingkungan Hidup dan Kehutan No. P.63/Menlhk/Setjen/ KUM.1/7/2016 tentang Persyaratan dan Tata Cara Penimbunan Limbah Bahan Berbahaya dan Beracun di Fasilitas Penimbusan Akhir. Di dalam peraturan ini terdapat ketentuan bahwa terhadap limbah B3 kategori 2 dari sumber spesifik khusus yang memiliki tingkat konsentrasi aktivitas lebih dari $1 \mathrm{~Bq} /$ gram untuk deret Uranium dan Thorium dan 10 Bq/gram untuk K-40, penimbunannya wajib dilakukan pada fasilitas penimbusan akhir (landfill) limbah B3 kelas II atau kelas I. Penghasil atau penimbun limbah B3 harus mengikuti ketentuan desain minimal untuk masingmasing kelas landfill sebagaimana diatur juga dalam peraturan ini [6].

Ancaman terbesar terhadap air tanah yang ditimbulkan oleh landfill adalah air lindi. Air lindi terdiri dari air dan senyawa yang terlarut dalam air yang terakumulasi ketika air bergerak melalui landfill. Air ini mungkin berasal dari hujan atau dari limbah itu sendiri. Air lindi dapat bermigrasi dari landfill dan mencemari tanah dan air tanah, sehingga menimbulkan risiko bagi kesehatan manusia dan lingkungan [7].

Pada penelitian ini akan dilakukan perbandingan laju lindi landfill Kelas I dan Kelas II pada fase operasional (tanpa penutup landfill) dan fase setelah penutupan (dengan penutup landfill) berdasarkan hasil menggunakan software pemodelan Hydrologic Evaluation of Landfill Performance (HELP) yang dikembangkan oleh United States Environmental Protection Agency (US EPA).

\section{METODE PENELITIAN}

\subsection{Persyaratan Landfill berdasarkan Peraturan \\ Peraturan Menteri Lingkungan Hidup dan Kehutanan No. P.63/Menlhk/Setjen}


/KUM.1/7/2016 tentang Persyaratan dan Tata Cara Penimbunan Limbah Bahan Berbahaya dan Beracun di Fasilitas Penimbusan Akhir mengatur pelaksanaan penimbunan Limbah B3 di fasilitas penimbusan akhir, yang mencakup ketentuan mengenai:

a. persyaratan fasilitas penimbusan Limbah B3;

b. persyaratan lokasi fasilitas penimbusan akhir Limbah B3;

c. tata cara penimbunan Limbah B3 di fasilitas penimbusan akhir Limbah B3;

d. tata cara dan persyaratan pemantauan lingkungan hidup;

e. tata cara dan rincian pelaksanaan penutupan bagian paling atas fasilitas penimbusan akhir Limbah B3; dan

f. penetapan penghentian kegiatan Penimbunan Limbah B3 pada fasilitas penimbusan akhir Limbah B3.
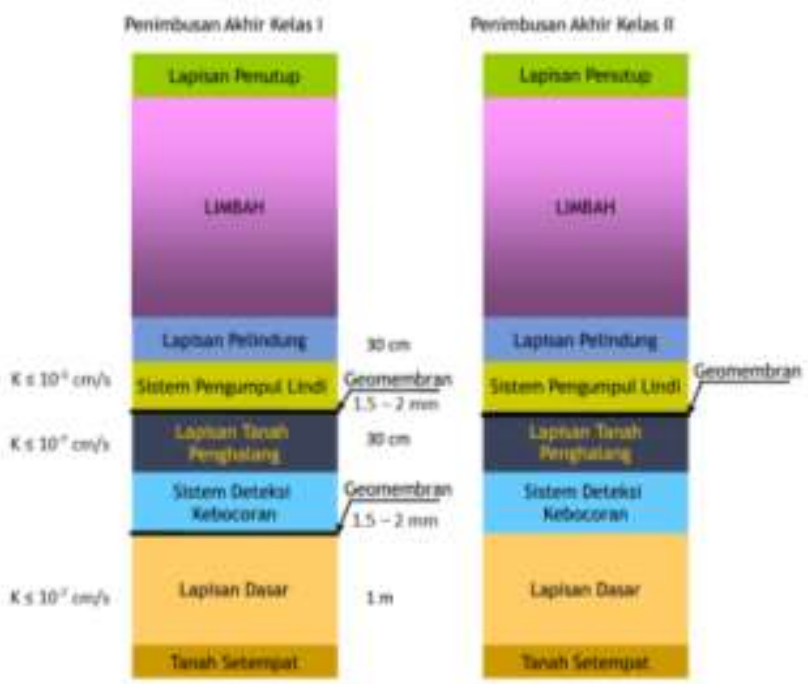

Gambar 1. Sistem Pelapis Landfill Kelas I dan Kelas II

Fasilitas penimbusan akhir (landfill) dikelompokan menjadi kelas I, kelas II, dan kelas III. Untuk limbah NORM diwajibkan untuk dibuang di landfill kelas I atau landfill kelas II.
Fasilitas penimbusan akhir Limbah B3 kelas I harus memiliki sistem pelapis yang berurutan, yaitu :

1. Lapisan dasar;

2. Lapisan geomembran kedua;

3. Lapisan untuk sistem pendeteksi kebocoran;

4. Lapisan tanah penghalang;

5. Lapisan geomembran pertama;

6. Lapisan untuk sistem pengumpulan dan pemindahan lindi (SPPL);

7. Lapisan pelindung selama operasi.

Sedangkan untuk landfill kelas II, harus memiliki sistem pelapis berurutan, yaitu :

1. lapisan dasar

2. lapisan untuk sistem pendeteksi kebocoran

3. lapisan tanah penghalang

4. lapisan geomembran

5. lapisan untuk sistem pengumpulan dan pemindahan lindi

6. lapisan pelindung selama operasi

Skema sistem pelapis untuk landfill kelas I dan kelas II dapat dilihat pada gambar 1.

\subsection{Pemodelan HELP}

Sumber utama lindi dari landfill meliputi cara-cara berikut.

- Resapan air hujan.

- Infiltrasi lindi permukaan.

- Infiltrasi air tanah.

- Air dalam limbah.

- Lindi dari bahan penutup

- Lindi yang dihasilkan dari dekomposisi bahan organik [8].

Water Balance Method adalah metode yang sederhana yang paling sering digunakan untuk memprediksi jumlah air lindi dari suatu landfill [9, 10]. Konfigurasi landfill 
yang dimodelkan dalam metode ini terdiri dari penutup landfill, kompartemen limbah, dan sistem pelapisan seperti yang terlihat dalam gambar 2 .

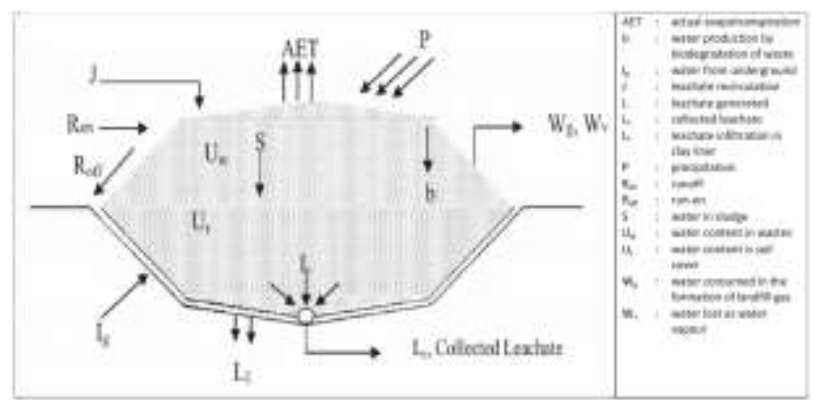

Gambar 2. Konfigurasi model Water Balance Method

Berbagai model komputer hidrologi telah dikembangkan untuk menghitung tingkat infiltrasi kontaminan. Beberapa model ini termasuk (a) Hydrologic Evaluation of Landfill Performance (HELP), (b) HYDRUS (2D / 3D), (c) model aliran tanah dan panas tak jenuh (UNSAT-H), (d) LandSim [11, 12]

Hydrologic Evaluation of Landfill Performance (HELP) merupakan model komputer yang mengadopsi metode water balance method [9]. Model HELP (versi 3.07) adalah alat yang paling banyak digunakan oleh United States Environmental Protection Agency (US EPA) untuk memprediksi kuantitas lindi dan menganalisa keseimbangan air di sistem lapisan landfill dan sistem penutupnya [11]. Sejumlah penelitian dilakukan untuk memperkirakan kuantitas lindi dan potensi perkolasi ke bawah permukaan menggunakan model HELP dalam beberapa tahun terakhir [13, 14, 15].

Model ini membutuhkan data cuaca, tanah dan desain, dan menggunakan teknik solusi yang memperhitungkan efek dari penyimpanan permukaan, limpasan, infiltrasi, evapotranspirasi, pertumbuhan vegetatif, penyimpanan kelembaban tanah, drainase bawah permukaan lateral, resirkulasi lindi, drainase vertikal tidak jenuh; dan kebocoran melalui tanah, geomembran atau lapisan komposit. Sistem landfill, termasuk berbagai kombinasi vegetasi, tanah penutup, sel limbah, lapisan drainase lateral, tanah permeabilitas rendah dan lapisan geomembran sintetis, dapat dimodelkan [16]. Tujuan utama dari model ini adalah untuk membantu dalam perbandingan antara alternatif desain, dalam hal keseimbangan air. Input model dapat dilihat pada Tabel 1.

\section{Tabel 1. Input Pemodelan HELP [16]}

\begin{tabular}{ll}
\multicolumn{1}{c}{ Tipe Data } & \multicolumn{1}{c}{ Parameter } \\
\hline Data Cuaca & Kedalaman Zona Evaporasi \\
\cline { 2 - 2 } & $\begin{array}{l}\text { Indeks Penutupan Daun } \\
\text { Maksimum }\end{array}$ \\
\cline { 2 - 2 } & Kelembaban Relatif \\
\cline { 2 - 2 } & Kecepatan Angin Rata-Rata \\
\cline { 2 - 2 } & Curah Hujan \\
\cline { 2 - 2 } & Temperatur \\
\hline Karakteristik & Penyinaran Matahari \\
\cline { 2 - 2 } Landfill & \% Kemungkinan Runoff \\
\hline $\begin{array}{l}\text { Data Tanah } \\
\text { dan Limbah } \\
\text { Padat }\end{array}$ & Tipe dan Tekstur Pelapis \\
\cline { 2 - 2 } & Ketebalan Pelapis \\
\hline
\end{tabular}

Pemodelan HELP membutuhkan data cuaca harian 1 sampai 100 tahun, parameter evapotranspiration, dan data tanah serta desain landfill [17]. Terdapat beberapa software yang dapat dipilih untuk menghasilkan data sintesis perkiraan cuaca harian dimasa yang akan datang. Salah satu software yang dpata digunakan untuk memproduksi data perkiraan cuaca harian di masa yang akan datang adalah LARS-WG $[18,19,20]$. 


\subsection{Skenario Pemodelan}

Tebal dan parameter teknis lapisan landfill yang akan digunakan dalam model mengikuti nilai yang ada dalam Peraturan Menteri Lingkungan Hidup dan Kehutanan Nomor P.63/Menlhk/Setjen/KUM.1/7/ 2016. Dengan ketebalan limbah sebesar 10 meter untuk masing-masing landfill.

Akan dilakukan 2 skenario untuk masing-masing landfill. Skenario pertama adalah landfill belum ditutup dengan rentang waktu simulasi 20 tahun, yang menggambarkan fase operasi landfill. Skenario kedua adalah landfill sudah tertutup sempurna dengan rentang waktu simulasi selama 100 tahun, yang menggambarkan fase setelah penutupan landfill.

Tabel 2. Jenis dan Ketebalan Lapisan Landfill Kelas I [6]

\begin{tabular}{|c|c|c|}
\hline No & Lapisan & $\begin{array}{c}\text { Ketebalan } \\
(\mathrm{m})\end{array}$ \\
\hline 1. & Top Soil-Fine Sandy Loam & 0.6000 \\
\hline 2. & $\therefore$ Tudung Drainase-Sand & 0.2000 \\
\hline 3. & $\square$ Geomembran-HDPE-2mm & 0.0020 \\
\hline 4. & Tudung Penghalang-Barrier Soil & 0.6000 \\
\hline 5. & Penutup Perantara-Fine Sandy Loam & 0.1500 \\
\hline 6. & 2 Limbah & 10.0000 \\
\hline 7. & Lapisan Pelindung-Sandy Clay Loam & 0.3000 \\
\hline 8. & $\therefore$ Pengumpul Lindi-Gravel & 0.3000 \\
\hline 9. & Geomembran Pertama-HDPE-2mm & 0.0020 \\
\hline 10. & Lapisan Penghalang-Barrier Soil & 0.3000 \\
\hline 11. & $\because$ Pendeteksi Kebocoran-Gravel & 0.3000 \\
\hline 12. & $\begin{array}{l}\text { Pendeteksi Kebocoran-Drainage Net } \\
(0.6 \mathrm{~cm})\end{array}$ & 0.0060 \\
\hline 13. & ${ }_{\text {Geomembran Kedua-HDPE-2mm }}$ & 0.0020 \\
\hline 14. & Lapisan Dasar-Barrier Soil & 1.0000 \\
\hline 15. & Tanah Lokal-Loamy Fine Sand & 4.0000 \\
\hline
\end{tabular}

Pada penelitian ini akan menggunakan data cuaca dari Stasiun Klimatologi Bogor. Data dari tahun 1984-2013 (30 tahun) akan digunakan untuk memproduksi 100 tahun data cuaca sintesis.
Tabel 3. Jenis dan Ketebalan Lapisan Landfill Kelas II

\begin{tabular}{|c|c|c|}
\hline No & Lapisan & $\begin{array}{l}\text { Ketebalan } \\
\text { (m) }\end{array}$ \\
\hline 1. & Top Soil-Fine Sandy Loam & 0.6000 \\
\hline 2. & $\therefore$ Tudung Drainase-Sand & 0.2000 \\
\hline 3. & $\square$ Geomembran-HDPE-2mm & 0.0020 \\
\hline 4. & 登Tudung Penghalang-Barrier Soil & 0.6000 \\
\hline 5. & Penutup Perantara-Fine Sandy Loam & 0.1500 \\
\hline 6. & Limbah & 10.0000 \\
\hline 7. & Lapisan Pelindung-Sandy Clay Loam & 0.3000 \\
\hline 8. & $\therefore$ Pengumpul Lindi-Gravel & 0.3000 \\
\hline 9. & Geomembran Pertama-HDPE-2mm & 0.0020 \\
\hline 10. & Lapisan Penghalang-Barrier Soil & 0.3000 \\
\hline 11. & $\therefore$ Pendeteksi Kebocoran-Gravel & 0.3000 \\
\hline 12. & $\begin{array}{l}-- \text { Pendeteksi Kebocoran-Drainage Net } \\
(0.6 \mathrm{~cm})\end{array}$ & 0.0060 \\
\hline 13. & Lapisan Dasar-Barrier Soil & 1.0000 \\
\hline 14. & Tanah Lokal-Loamy Fine Sand & 4.0000 \\
\hline
\end{tabular}

Tabel 4. Parameter yang Digunakan

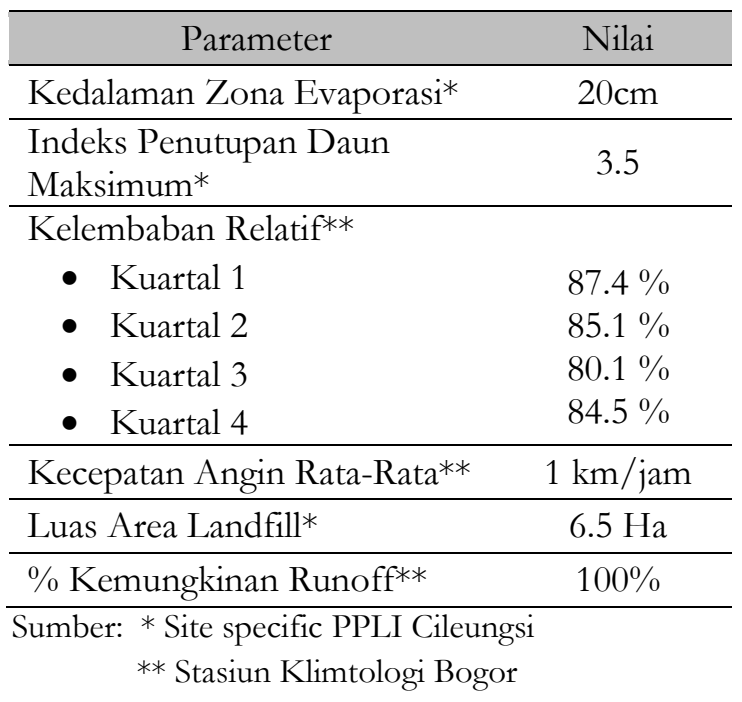

Simulasi dilakukan untuk landfill kelas I dan Kelas II sesuai skenario fase operasional (tanpa penutup) dan fase stelah penutupan (dengan penutup). Data jenis lapisan dan ketebalan untuk masing-masing landfill dapat dilihat pada tabel 2 dan 3. Tabel 4 adalah data lain yang digunakan dalam penelitian ini. 


\section{HASIL DAN PEMBAHASAN}

\subsection{Laju Produksi air lindi landfill fase operasional (tanpa penutup)}

Dari simulasi yang telah dilakukan diperoleh rata-rata laju produksi air lindi untuk beberapa lapisan. Perbandingan laju produksi air lindi rata-rata dalam 20 tahun untuk landfill kelas I dan kelas II dapat dilihat pada tabel 5 .

Dari tabel 5 dapat dilihat bahwa terdapat perbedaan yang cukup besar antara laju lindi dari lapisan dasar landfill kelas I dan landfill kelas II. Landfill kelas I mampu menahan laju lindi lebih baik dari pada landfill kelas II. Hal ini karena landfill kelas I memiliki 2 lapisan geomembran berupa HDPE dengan ketebalan $2 \mathrm{~mm}$. Landfill kelas I memang dipersyaratkan untuk limbah dengan tingkan bahaya yang lebih tinggi dibandingkan limbah yang dibuang pada landfill kelas II.

Tabel 5. Perbandingan Laju Lindi Landfill Kelas I dan II untuk Skenario tanpa Penutup

\begin{tabular}{lcccc}
\hline \multirow{2}{*}{ Lapisan } & \multicolumn{2}{c}{ Landfill Kelas I } & \multicolumn{2}{c}{ Landfill Kelas II } \\
\cline { 2 - 5 } & $\begin{array}{c}\text { Laju lindi } \\
\text { rata-rata } \\
(\mathrm{mm} / \mathrm{thn})\end{array}$ & SD & $\begin{array}{c}\text { Laju lindi } \\
\text { rata-rata } \\
(\mathrm{mm} / \mathrm{thn})\end{array}$ & SD \\
\hline Curah Hujan & 3658.87 & 482.067 & 3658.87 & 482.067 \\
\hline $\begin{array}{l}\text { Lindi dari } \\
\text { Lapisan } \\
\text { Pelindung }\end{array}$ & 2434.323 & 349.394 & 2434.323 & 349.394 \\
\hline $\begin{array}{l}\text { Lindi dari } \\
\text { Lapisan } \\
\text { Penghalang }\end{array}$ & 0.05645 & 0.00724 & 0.05645 & 0.00724 \\
\hline $\begin{array}{l}\text { Lindi dari } \\
\begin{array}{l}\text { Lapisan } \\
\text { Dasar }\end{array}\end{array}$ & 0.0016 & 0.00074 & 0.05725 & 0.00919 \\
\hline
\end{tabular}

Tabel 6. Perbandingan Laju Lindi Landfill Kelas I \& II untuk Skenario dengan Penutup

\begin{tabular}{lcccc}
\hline \multirow{2}{*}{ Lapisan } & \multicolumn{2}{c}{ Landfill Kelas I } & \multicolumn{2}{c}{ Landfill Kelas II } \\
\cline { 2 - 5 } & $\begin{array}{c}\text { Laju lindi } \\
\text { rata-rata } \\
(\mathrm{mm} / \mathrm{thn})\end{array}$ & SD & $\begin{array}{c}\text { Laju lindi } \\
\text { rata-rata } \\
(\mathrm{mm} / \mathrm{thn})\end{array}$ & SD \\
\hline Curah Hujan & 3744.93 & 453.328 & 3744.93 & 453.328 \\
\hline
\end{tabular}

\begin{tabular}{lcccc}
\hline $\begin{array}{l}\text { Lindi dari } \\
\text { tudung } \\
\text { penghalang }\end{array}$ & 0.88509 & 0.01738 & 0.88510 & 0.01737 \\
\hline $\begin{array}{l}\text { Lindi dari } \\
\text { Lapisan } \\
\text { Pelindung }\end{array}$ & 0.88509 & 0.01742 & 0.88511 & 0.01738 \\
\hline $\begin{array}{l}\text { Lindi dari } \\
\text { Lapisan } \\
\text { Penghalang }\end{array}$ & 0.00011 & 0.00000 & 0.00011 & 0.00000 \\
\hline $\begin{array}{l}\text { Lindi dari } \\
\text { Lapisan } \\
\text { Dasar }\end{array}$ & 0.00007 & 0.00000 & 0.00011 & 0.00000 \\
\hline
\end{tabular}

\subsection{Laju Produksi air lindi landfill fase} setelah penutupan (dengan penutup)

Dari simulasi yang telah dilakukan diperoleh rata-rata laju produksi air lindi untuk beberapa lapisan. Perbandingan laju produksi air lindi rata-rata dalam 100 tahun untuk landfill kelas I dan kelas II dapat dilihat pada tabel 6 .

Dari tabel 6, untuk skenario landfill dengan penutup. Tidak ditemukan perbedaan yang signifikan antara laju lindi dari semua lapisan landfill baik pada landfill kelas I maupun kelas II. Hal ini karena kedua landfill meliki persyaratan lapisan penutup yang sama. Hampir sebagian besar air yang masuk ke landfill sudah tertahan oleh tudung geomembran yang berupa HDPE dengan ketebalan $2 \mathrm{~mm}$. Sehingga dapat dikatakan untuk fase setelah penutupan, landfill kelas I dan kelas II memiliki kinerja yang sama dalam hal menahan laju produksi air lindi.

\section{KESIMPULAN}

Untuk fase operasional ditemukan perbedaan laju lindi dari lapisan dasar yang signifikan antara landfill Kelas I dan Kelas II. Hal ini karena Landfill kelas I memiliki 2 lapisan geomembran HDPE sedangkan Landfill kelas II hanya memilki 1 geomembran.

Perbedaan ini menunjukan bahwa landfill kelas I memang ditujukan untuk 
menampung limbah yang lebih berbahaya daripada limbah yang dibuang di landfill kelas II.

Untuk fase setelah penutupan limbah, landfill kelas I dan kelas II memiliki kinerja yang sama dalam hal menahan laju produksi air lindi.

\section{DAFTAR PUSTAKA}

[1] Doyi, I.N., Essumang, D.K., Dampare, S.B., \& Glover, E.T. (2016). Technologically Enhanced Naturally Occurring Radioactive Materials (TENORM) in the Oil and Gas Industry: A Review. Reviews of environmental contamination and toxicology, 238, 107-119.

[2] Ali, Kamal K., Shafik, Shafik Sh., Husain, Husain A. (2017). Radiological Assessment of NORM Resulting From Oil and Gas Production Processing in South Rumaila Oil Field, Southern Iraq. Iraqi Journal of Science, 2017, Vol. 58, No.2C, pp: 1037-1050.

[3] Husain, H., Sakhnini, L. (2016) Radiological impact of NORM generated by oil and gas industries in the kingdom of Bahrain. Journal of Environmental Radioactivity $\quad \mathrm{xxx} \quad$ (2016) 1-7, http://dx.doi.org /10.1016/j.jenvrad.2016.12.004.

[4] International Association of Oil \& Gas Producers (OGP). (2008). Guidelines for the management of Naturally Occurring Radioactive Material (NORM) in the oil \& gas industry, Report 412. London, UK.

[5] Peraturan Pemerintah Republik Indonesia No. 101 Tahun 2014 Tentang Pengelolaan Limbah Bahan Beracun dan Berbahaya (B3).
[6] Kementerian Lingkungan Hidup dan Kehutanan. (2016). Peraturan Menteri Lingkungan Hidup dan Kehutanan Nomor P.63/Menlhk/Setjen/KUM.1/7/2016 tentang Persyaratan dan Tata Cara Penimbunan Limbah Baban Berbahaya dan Beracun di Fasilitas Penimbusan Akhir. Jakarta-Indonesia, KLHK.

[7] Hughes, K. Christy, A. Heimlich, J. (2018). Landfill Types and Liner Systems. Ohio State University Extension Fact Sheet CDFS-138-05. http://ohioline. osu.edu (2018).

[8] Youcai, Zhao. (2018). Leachate Generation and Characteristics. Pollution Control Technology for Leachate from Municipal Solid Waste 2018, Pages 1-30.

[9] El-Fadel, M., Findikakis, A. N., Leckie, J. O. (1997). Modeling Leachate Generation and Transport in Solid Waste Landfills. Environmental Technology, 18:7, 669686.

[10] São Mateus, MSC., Costa, MS., Machado, SL. (2012). An attempt to perform water balance in a Brazilian municipal solid waste landfill. Waste Management 32: 471-481.

[11] Yong, Raymon N., Mulligan, Catherine N., Fukue, Masaharu. (2015). Sustainable Practices in Geoenvironmental Engineering. CRC Press Taylor \& Francis Group, Boca Raton.

[12] Butt, T.E., Alam, A., Gouda, H.M., Paul, P., Mair, N. (2016). Baseline study and risk analysis of landfill leachate - Current state-of-the-science of computer aided approaches. Sci Total Environ (2016).

[13] Frikha,Youssef., Fellner, Johann., Zairi, Moncef. (2017). Leachate generation from landfill in a semi-arid climate: A qualitative 
and quantitative study from Sousse, Tunisia. Waste Management \& Research 1-9.

[14] Alslaibi,Tamer M., Abustan, Ismail., Mogheir, Yunes K., Afifi, Samir. (2013). Quantification of leachate discharged to groundwater using the water balance method and the Hydrologic Evaluation of Landfill Performance (HELP) model. Waste Management \& Research 31(1) 50-59.

[15] Bou-Zeid, E., El-Fadel, M. (2004). Parametric sensitivity analysis of leachate transport simulations at landfills. Waste Management 24 (2004) 681-689.

[16] Schroeder, P.R., Aziz, N.M., Lloyd, C.M., Zappi, P.A.(1994). The Hydrologic Evaluation of Landfill Performance (HELP) Model. User's Guide for Version 3. EPA/600/R- 94/168a. US EPA Risk Reduction Engineering Laboratory. Cincinnati, Ohio, 84 p. and appendix.

[17] Berger, Klaus U. (2015). On the current state of the Hydrologic Evaluation of Landfill Performance (HELP) model. Waste Management 38 (2015) 201-209.
[18] Hassan, Zulkarnain., Shamsudin, Supiah., Harun, Sobri., (2014). Application of SDSM and LARS-WG for simulating and downscaling of rainfall and temperature. Theoretical and Applied Climatology April 2014, Volume 116, Issue 1-2, pp 243-257.

[19] Osman, Yassin., Al-Ansari, Nadhir., Abdellatif, Mawada., Aljawad, Sadeq B., Knutsson, Sven. (2014). Expected Future Precipitation in Central Iraq Using LARSWG Stochastic Weather Generator. Engineering 6, 948-959.

[20] Karimi, Sepideh., Karimi, Saeed., Yavari, Ahmad Reza., Niksokhan, Mohamad Hosein. (2015). Prediction of Temperature and Precipitation in Damavand Catchment in Iran by Using LARS -WG in Future. Earth Sciences. Vol. 4, No. 3, 2015, pp. 95-100. 